\title{
Evaluation of an autologous cancer vaccine for the treatment of metastatic canine hemangiosarcoma: a preliminary study
}

\author{
Michael D. Lucroy ${ }^{1 *}$ (D), Ryan M. Clauson', Mark A. Suckow², Ferris El-Tayyeb and Ashley Kalinauskas ${ }^{1}$
}

\begin{abstract}
Background: Canine hemangiosarcoma (HSA) is an aggressive cancer arising from multipotential bone marrowderived stem cells. Anthracycline chemotherapy drugs have been the mainstay adjuvant chemotherapy following surgery with only modest improvement in survival and an attendant risk for adverse events. Immunotherapy, using a whole cell autologous cancer vaccine adjuvanted with MIM-SIS, may improve outcomes for dogs with HSA with a lower risk for adverse events compared with chemotherapy.
\end{abstract}

Results: In cultured DH82 canine monocyte-like cells, autologous cancer vaccines prepared from 13 dogs with HSA increased MHC-II surface expression ranging from 20.0-60.4\% on single-stained cells, CD80 surface expression ranging from $23.7-45.9 \%$ on single-stained cells, and MHC-II/CD80 surface expression ranging from 7.2-20.1\% on double-stained cells. Autologous cancer vaccines were able to, on average, stimulate an up-regulation of MHC-II and CD80 by 48-fold as compared to media only (MHC-II + CD80 + cells: $12.19 \pm 3.70 \%$ vs. $0.25 \pm 0.06 \% ; p<0.001)$. The overall median survival time for dogs treated with the autologous cancer vaccine was 142 days (range, 61 to 373 days). Dogs treated with the autologous cancer vaccine or maximum tolerated dose (MTD) chemotherapy had significantly $(P<0.001)$ longer survival than dogs treated with surgery alone. The 1 -year survival rate was $12.5 \%$ for dogs treated with the autologous cancer vaccine, and $0 \%$ for dogs treated with surgery alone or MTD chemotherapy. No adverse events were observed in the dogs treated with the autologous cancer vaccine.

Conclusions: The adjuvanted autologous cancer vaccine is capable of up-regulating MHC-II and CD80 in cultured canine monocyte-derived cells, which are important stimulatory molecules in generating an immune response and improves survival time in dogs with metastatic (stage III) HSA when compared to surgical treatment alone. Autologous cancer vaccine-treated dogs had survival similar to those dogs treated with MTD chemotherapy without any observed adverse events. This autologous cancer vaccine represents an effective form of individualized immunotherapy that is an appealing option for dog owners not wanting to pursue adjuvant chemotherapy for HSA.

Keywords: Immunotherapy, Canine hemangiosarcoma, CD80, MCHII, Autologous cancer vaccine

\footnotetext{
*Correspondence: mlucroy@torigen.com

${ }^{1}$ Torigen Pharmaceuticals, Inc, 400 Farmington Avenue R1855 CB129, 06032

Farmington, CT, USA

Full list of author information is available at the end of the article
}

\section{$\triangle B M C$}

(c) The Author(s). 2020 Open Access This article is licensed under a Creative Commons Attribution 4.0 International License, which permits use, sharing, adaptation, distribution and reproduction in any medium or format, as long as you give appropriate credit to the original author(s) and the source, provide a link to the Creative Commons licence, and indicate if changes were made. The images or other third party material in this article are included in the article's Creative Commons. licence, unless indicated otherwise in a credit line to the material. If material is not included in the article's Creative Commons licence and your intended use is not permitted by statutory regulation or exceeds the permitted use, you will need to obtain permission directly from the copyright holder. To view a copy of this licence, visit http://creativecommons.org/licenses/by/4.0/ The Creative Commons Public Domain Dedication waiver (http://creativecommons.org/publicdomain/zero/1.0/) applies to the data made available in this article, unless otherwise stated in a credit line to the data. 


\section{Background}

Canine hemangiosarcoma (HSA) is an aggressive, ultimately fatal, cancer arising from multipotential bone marrow-derived stem cells that arrest their differentiation at the hemangioblast or angioblast stage [1]. Based on gene expression profiling revealing upregulation of VEGF, MMPs, TIMPs, etc. and enrichment of cytokines, it appears inflammation and angiogenesis are two important processes in the pathogenesis of canine HSA [2]. The HSA microenvironment has also been shown to enhance tumor growth and promote migration of tumor cells through chemokines such as IL- 8 and CXCL12 and modified sphingosines [3]. The spleen is the most common site of HSA in the dog, although liver, heart, and skeletal muscle may also be sites of origin [3, 4]. After splenectomy, or wide surgical excision at other sites, reported median survival times range from 19 to 110 days, with death typically due to widespread metastasis which often results in significant hemorrhage [4-10]. Dogs with metastatic disease at the time of diagnosis (stage III) have a poor prognosis, with reported median survival times from 23 to 40 days following surgical removal of the primary tumor $[5,9,10]$.

For nearly 30 years, anthracycline chemotherapy drugs (most notably doxorubicin) have been the mainstay adjuvant chemotherapy following splenectomy, and modestly prolongs survival of affected dogs. When combined with surgery, doxorubicin-based chemotherapy protocols have reported median survival times ranging from 140 to 202 days [11]. Epirubicin, another anthracycline drug, has a reported median survival time of 144 days when used to treat canine splenic HSA after splenectomy [12]. Combining doxorubicin with other chemotherapy drugs does not typically prolong patient survival, and additions of toceranib, vincristine with cyclophosphamide, or metronomic cyclophosphamide, have reported median survival times of 172, 145 and 202 days, respectively, in populations of dogs that included those without metastatic disease (stage I and II) [13-15]. However, the addition of dacarbazine has been reported to increase the median survival time to $>550$ days in a group of 9 dogs with stage II HSA [16]. Doxorubicin chemotherapy is modestly effective for dogs with stage III HSA, extending the median survival time to 107 to 140 days [10, 17]. Altered expression of the ATPbinding cassette transporters ABCB1 and ABCG2 may be partly responsible for the inherent drug resistance observed in canine HSA [18].

In addition to the potential for prolonging survival in dogs with HSA, chemotherapy also has the potential to cause adverse events. In dogs with stage III HSA treated with anthracycline chemotherapy, $43.5 \%$ had adverse events, with $21.7 \%$ of treated dogs requiring hospitalization for supportive care [10]. The combination of doxorubicin, vincristine and cyclophosphamide
(VAC protocol) to treat canine HSA caused neutropenia in $73 \%$ of dogs, $27 \%$ had severe gastrointestinal (GI) adverse events, and 13\% developed sepsis [14]. Epirubicin is also reported to have a high rate of adverse events when used to treat cancer-bearing dogs [19]. Despite the positive effect on survival for cancer-bearing dogs, recent findings show that the majority of surveyed pet owners would not pursue chemotherapy due to concerns about the risk for adverse events [20].

Immunotherapy is another treatment option that may improve patient outcomes for dogs with HSA with a lower risk for adverse events compared with chemotherapy. An allogenic vaccine, consisting of lysates from two canine HSA cell lines and a liposome-DNA adjuvant, was administered to 28 dogs with various forms of HSA via intraperitoneal (IP) injection [21]. In subset analysis of 13 dogs with stage II HSA treated with only doxorubicin and the vaccine, the reported median survival time was 182 days, which is similar to chemotherapy alone. A dendritic cell vaccine was evaluated in 5 dogs with splenic HSA [22]. Monocytes isolated from peripheral blood were incubated with tumor-derived mRNA to create the vaccine, which was administered via IP injection. The dogs were also treated with doxorubicin $\left(20 \mathrm{mg} / \mathrm{m}^{2}\right)$. The reported median survival time was 109 days. Both of these vaccine approaches were reportedly well-tolerated.

Autologous tissue vaccine is another immunotherapy option for dogs with HSA. Autologous tissue vaccines consist of cells harvested from the patient's own tumor, which presents the full repertoire of the patient's unique tumor-associated antigens (TAA) to the immune system. A method of creating autologous tumor vaccines for dogs has been recently described, and relies on enzymatic cell dissociation, which could destroy TAA [23]. Although some humoral response was described in the treated dogs, survival outcome was not reported for the single dog with HSA in that study population.

Another method of autologous cancer immunotherapy is a whole cell autologous cancer vaccine, described herein. Cancer cells reproduce within a mesh of supporting tumor stroma, and reciprocal interactions between neoplastic cells and their surrounding microenvironment are critical factors in tumor progression. Many anticancer immunotherapies have focused on persuading the host immune system to recognize specific TAA; however, the ability for tumor destruction by such vaccines has been disappointing, perhaps because TAA are lost over time in the growing tumor, do not represent the full repertoire of antigens, and/or the host grows tolerant to them. For this reason, we chose an approach that presents the immune system with a broad menu of antigen targets, including those that are associated with neoplastic cells and those that are associated with the tumor stroma that is essential to tumor growth and spread. 
This whole cell autologous cancer vaccine is generated by a novel method of mechanically dissociating tumor cells followed by chemical inactivation, to preserve TAA, and then mixing the cellular material with MIM-SIS (matrix immunomodulator, small intestine submucosaderived), a protein immune adjuvant [24]. Extracellular matrix bioscaffolds used in tissue and wound repair applications are pro-inflammatory, and modulation of macrophage phenotype is believed to play an important role in the mechanism of action [25]. Because of this ability to drive the immune response, medical grade SIS has been evaluated for use as an adjuvant for therapeutic cancer vaccines. Immunotherapy with this whole cell MIM-SIS adjuvanted autologous cancer vaccine has shown efficacy in rodent models of prostate cancer [26-28]. These data support the idea that MIM-SIS may be effective when used as an adjuvant for tissue vaccines in a clinical situation. With this approach, tumor cells are not cultured, avoiding the changes in antigenic profiles that occur in vitro as demonstrated by microarray analysis [29]. This autologous cancer vaccine also appears to be welltolerated by cancer-bearing dogs [24].

With therapeutic cancer vaccines, the goal is to increase presentation of TAA to the immune system, thereby increasing activation of tumor-specific $\mathrm{T}$ cells, favoring the elimination and equilibrium stages of cancer immunoediting in the host [30]. The result is an enhanced ability of the immune system to destroy cancer cells, stop or slow the growth of cancer cells, or delay metastasis which can improve patient survival. The purpose of this study was to determine the in vitro effects of this whole cell adjuvanted autologous cancer vaccine on a canine monocyte cell line, and determine the effect on postoperative survival of dogs with metastatic HSA when compared to a historical control group of dogs with metastatic HSA treated with either surgery alone or surgery followed by standard anthracycline-based chemotherapy protocols.

\section{Results}

\section{Mechanism of action assay}

Surrogate autologous cancer vaccine preparations were formulated from 13 dogs with HSA of variable origin and stage (Table 1). These surrogate vaccines were utilized to assess their immunostimulatory potential in vitro in terms of their ability to stimulate antigen presentation (MHC-II) and co-stimulation (CD80) in canine DH82 cells evaluated via flow cytometry (Fig. 1). From this analysis, it was demonstrated that autologous cancer vaccines increased MHC-II surface expression ranging from $20.0-60.4 \%$ on single-stained cells (Fig. 2ab), CD80 surface expression ranging from $23.7-45.9 \%$ on single-stained cells (Fig. 2c-d), and MHC-II/CD80 surface expression ranging from $7.2-20.1 \%$ on doublestained cells (Fig. 2e-f). Notably, autologous cancer vaccines $(n=13)$ were able to, on average, stimulate an up-regulation of MHC-II and CD80 by 48 -fold as compared to media only (MHC-II + CD80 + cells: $12.19 \pm$ $3.70 \%$ vs. $0.25 \pm 0.06 \% ; p<0.001)$. As compared to autologous cells alone without MIM-SIS adjuvant, autologous cancer vaccines increased the expression of MHC-II and CD80 by $53.7 \%$ (MHC-II + CD80 + cells: $12.19 \pm 3.70 \%$ vs. $7.93 \pm 0.46 \% ; p=0.18$ ). Lastly, as compared to MIM-SIS adjuvant only, autologous cancer vaccines increased the expression of MHC-II and CD80 by

Table 1 Characteristics of dogs with hemangiosarcoma utilized for mechanism of action evaluation

\begin{tabular}{|c|c|c|c|c|c|c|}
\hline Patient & Breed & Age (y) & Sex/Status ${ }^{b}$ & Weight (kg) & Primary & Metastasis \\
\hline $16-034$ & Mixed & 6 & $\mathrm{~F} / \mathrm{S}$ & 12.2 & Subcutaneous & No \\
\hline 18-082 & Golden retriever & $N R^{a}$ & $M / C$ & 40.9 & Liver & Yes \\
\hline 19-039 & Mixed & 12 & $\mathrm{M} / \mathrm{C}$ & 36.2 & Subcutaneous & No \\
\hline 19-060 & Boxer & 7 & $M / I$ & 29.5 & Subcutaneous & No \\
\hline 19-195 & Rottweiler & 3 & $F / S$ & 34.9 & Bone $^{c}$ & No \\
\hline 19-199 & Labrador retriever & 12 & $M / C$ & NR & Spleen & No \\
\hline 19-261 & Golden retriever & 10 & $F / S$ & 25.9 & Spleen & No \\
\hline 20-008 & Mixed & NR & $\mathrm{M} / \mathrm{C}$ & 12.2 & Spleen & No \\
\hline 20-010 & Coonhound & 7 & $F / S$ & 31.8 & Spleen & No \\
\hline 20-020 & Mixed & 13 & $\mathrm{M} / \mathrm{C}$ & 22.7 & Subcutaneous & No \\
\hline 20-025 & English Setter & 14 & $M / C$ & 31.6 & Spleen & No \\
\hline $20-027$ & Mixed & 10 & $\mathrm{M} / \mathrm{C}$ & 24.0 & Spleen & No \\
\hline 20-040 & Mixed & 10 & $M / C$ & 41.5 & Spleen & Yes \\
\hline
\end{tabular}

${ }^{a} N R$ Not reported

${ }^{\mathrm{b}} F$ female, $M$ male, $S$ spayed, $C$ castrated, $I$ intact

'The submitting veterinarian did not pursue immunohistochemisty, so telangiectatic osteosarcoma is not excluded. However the pathologist did not find anything to support osteosarcoma in the tissue sectons examined 


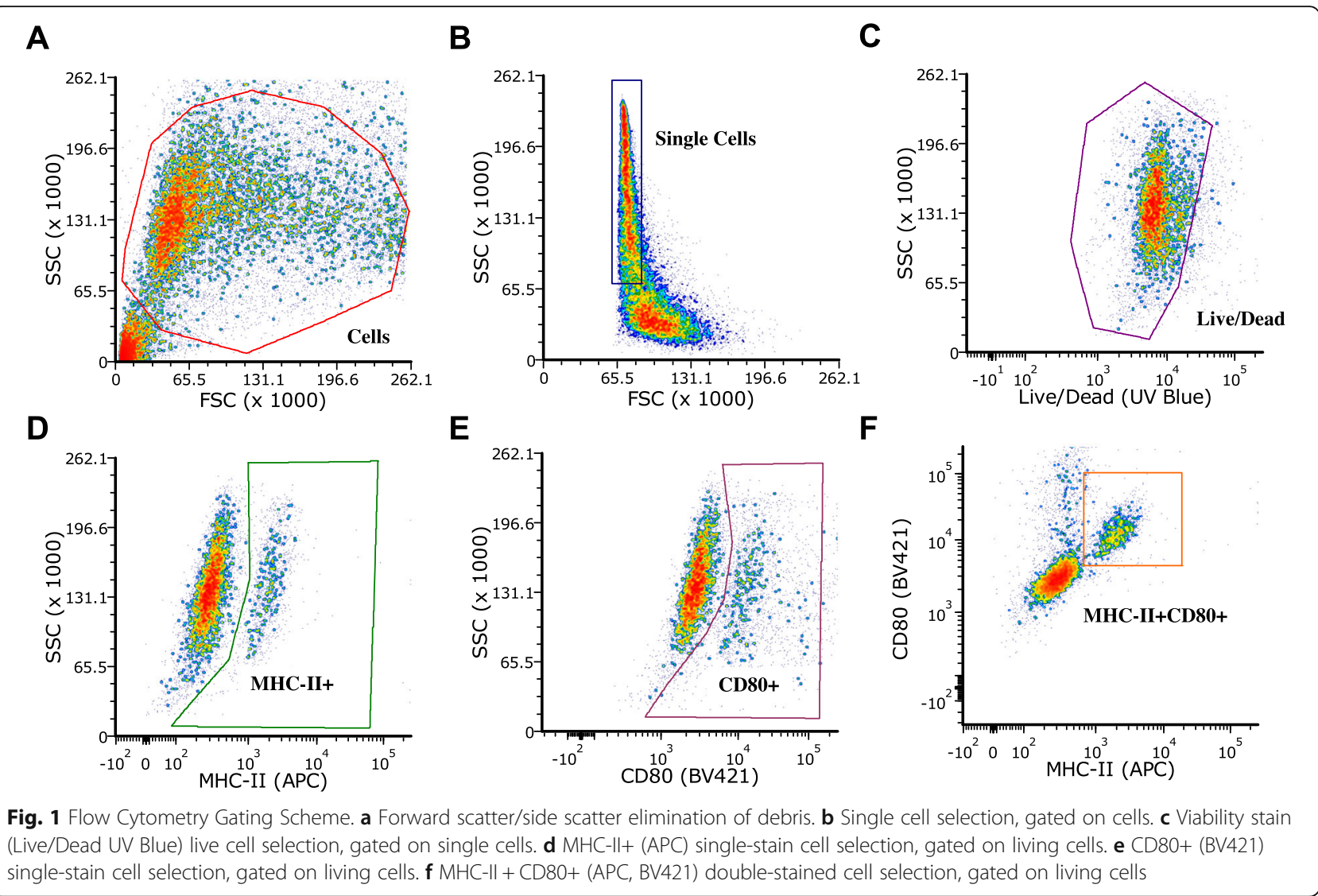

9-fold (MHC-II + CD80 + cells: $12.45 \pm 3.53 \%$ vs. $1.33 \pm$ $0.36 \% ; p<0.001)$.

\section{Study population Cases}

There were 32 dogs with HSA identified within the Torigen database, and 8 dogs met the entry criteria (Table 2). Of the 24 dogs that were excluded, 10 had stage I or II disease, 9 dogs had incomplete medical records, and 5 dogs had no staging tests done by the attending veterinarian. Six different pure breeds were represented, including 2 (25\%) German Shepherd Dogs and $1(13 \%)$ each of golden retriever, Labrador retriever, great Dane, standard poodle and Australian cattle dog. There was 1 (13\%) mixed breed dog. The mean age at diagnosis was $7.6 \pm 1.71$ years (range, $7-10$ years). The mean patient weight was $39.5 \pm 11.83 \mathrm{~kg}$ (range, 22.4$54.7 \mathrm{~kg})$. There were $7(88 \%)$ males (1 intact) and 1 (12\%) spayed female. HSA was diagnosed within the spleen in 7 dogs (88\%) and was subcutaneous in 1 dog (12\%). Of the 7 dogs with splenic HSA, 4 (57\%) were reported to have hemoperitoneum at the time of diagnosis. Disseminated disease included metastasis to the liver $(n=3)$, lungs $(n=3)$, right atrium $(n=1)$ and omentum $(n=1)$. The mean time from surgery until the starting the vaccine series was $17 \pm 6$ days.

\section{Historical controls}

There were 42 dogs in the surgery only group. Twelve different pure breeds were represented, including 9 (21\%) German Shepherd Dogs 5 (12\%) Labrador retrievers, 3 (7\%) border collies, 2 (5\%) each of boxers and beagles, and 1 (2\%) each of American pit bull terrier, English setter, cane corso, golden retriever, Airedale terrier, Newfoundland, and rottweiler. There were 14 (33\%) mixed breed dog. The mean age at diagnosis was $10.3 \pm$ 2.00 years (range, $6-14$ years). The mean patient weight was $30.2 \pm 5.96 \mathrm{~kg}$ (range, 15.0-52.8 kg). There were 22 (52\%) males (11 intact) and 20 (48\%) females (6 intact). HSA was diagnosed within the spleen in all 42 dogs. The presence or absence of hemoperitoneum at the time of diagnosis was not reported in the data set provided. Disseminated disease included metastasis to the liver $(n=$ $26)$, omentum $(n=8)$, lungs $(n=4)$, hepatic lymph nodes $(\mathrm{n}=2)$, right atrium $(n=1)$ and pleura $(n=1)$.

There were 23 dogs in the maximum tolerated dose (MTD) chemotherapy group. group. Eight different pure breeds were represented, including 8 (35\%) German Shepherd Dogs, 2 (9\%) Labrador retrievers, and 1 (4\%) each of golden retriever, cane corso, Brittany, beagle, 


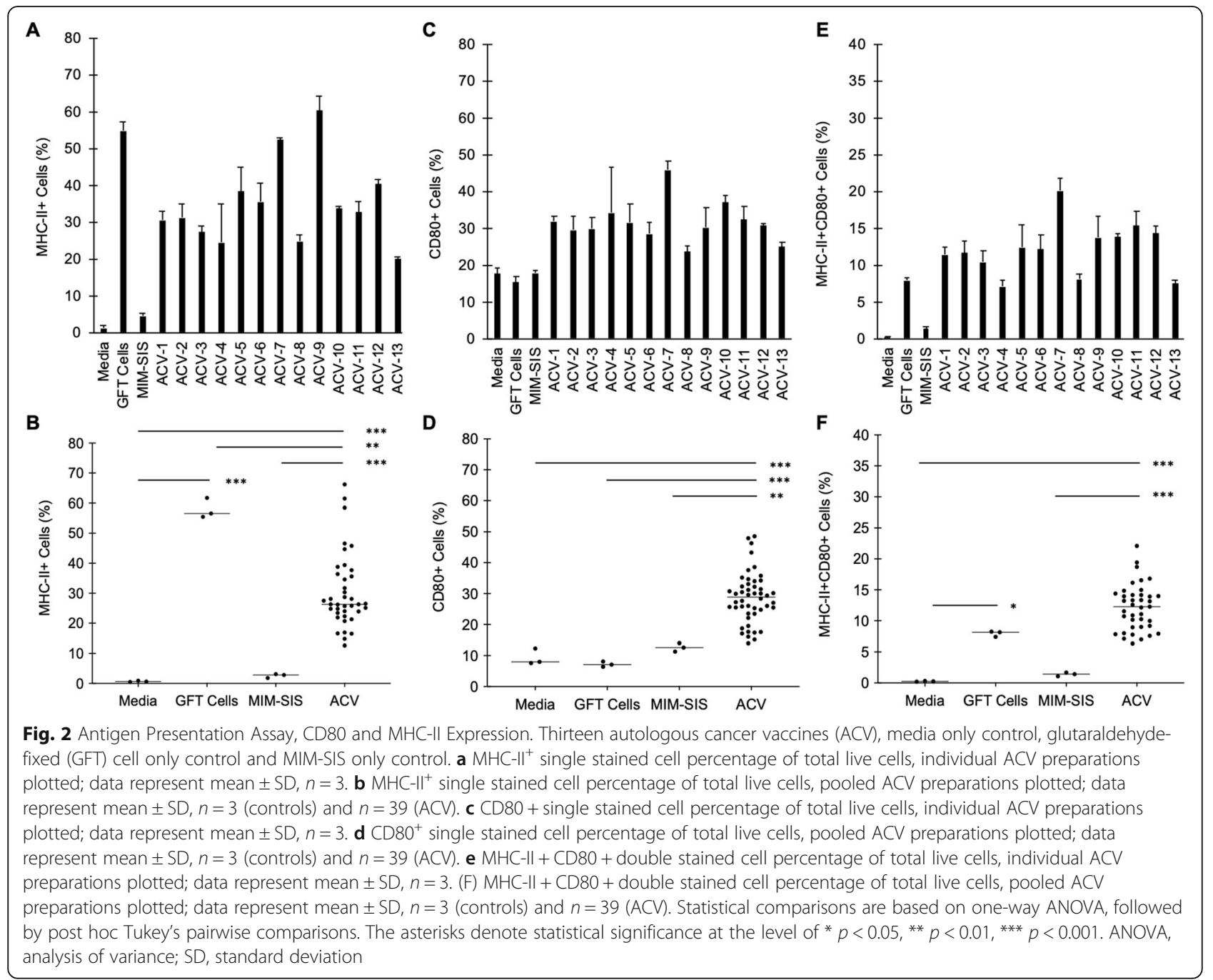

dachshund, and Czechoslovakian wolf dog. There were 7 (30\%) mixed breed dogs. The mean age at diagnosis was $10.0 \pm 2.21$ years (range, $7-14$ years). The mean patient weight was $31.6 \pm 9.84 \mathrm{~kg}$ (range, $5.1-47.0 \mathrm{~kg}$ ). There were 14 (61\%) males (12 intact) and 9 (39\%) females (4 intact). HSA was diagnosed within the spleen in all 23 dogs. Information regarding hemoperitoneum at diagnosis was not described in the shared data set. Disseminated disease included metastasis to the liver $(n=16)$, omentum $(n=5)$ and lungs $(n=1)$. In the MTD chemotherapy group, standard anthracycline-based protocols were used, and 17 (74\%) dogs were treated with doxorubicin, 3 (13\%) dogs were treated with epirubicin, $2(9 \%)$ dogs were treated with doxorubicin and cyclophosphamide, and 1 (4\%) dog was treated with doxorubicin and dacarbazine.

The proportion of male dogs was significantly higher in the autologous cancer vaccine group when compared to the surgery only group $(\mathrm{p}<0.05)$. The proportion of male dogs was not significantly different between the autologous cancer vaccine and MTD chemotherapy groups. There were no significant differences in variance of weights or ages among of the treatment groups.

\section{Clinical outcomes Adverse events}

In the 8 dogs treated with the adjuvanted autologous cancer vaccine, no episodes of anaphylaxis or other adverse events were reported following any of the 24 doses administered. In the dogs treated with MTD chemotherapy, 10 (43\%) dogs were reported to have at least 1 adverse event, and 4 of the 10 dogs had multiple adverse events. Overall, 4 (17\%) dogs required hospitalization for grade 3-4 bone marrow toxicity $(n=2)$ and grade 3 GI toxicity $(n=2)$.

\section{Survival}

Progressive HSA was the cause of death in all dogs that died during the follow-up period in both the historical control group and autologous cancer vaccine group. Four dogs were right-censored (1 dog treated with the 
Table 2 Characteristics of dogs with stage III hemagiosarcoma treated with surgery and the autologous cancer vaccine

\begin{tabular}{|c|c|c|c|c|c|c|}
\hline Patient & Breed & Age (y) & Sex/Status ${ }^{b}$ & Weight (kg) & Primary & Hemoabdomen \\
\hline $15-049$ & Great Dane & 7 & $\mathrm{~F} / \mathrm{S}$ & 54.7 & Spleen & $Y$ \\
\hline $16-008$ & Standard poodle & 6 & $M / C$ & 22.4 & Subcutaneous & \\
\hline 18-082 & Golden retriever & $N R^{a}$ & $\mathrm{M} / \mathrm{C}$ & 40.9 & Liver & NR \\
\hline $18-216$ & German shepherd dog & 7 & $M / C$ & 40.9 & Liver & Y \\
\hline 19-023 & German shepherd dog & 6 & $M / C$ & 54.5 & Liver & $\mathrm{N}$ \\
\hline $19-120$ & Australian cattle dog & 10 & $M / I$ & 25.0 & Spleen & Y \\
\hline 19-167 & Labrador retriever & 7 & $M / C$ & 36.4 & Spleen & Y \\
\hline $20-040$ & Mixed & 10 & $M / C$ & 41.5 & Spleen & $\mathrm{N}$ \\
\hline
\end{tabular}

\section{${ }^{\mathrm{a}} \mathrm{NR}$ Not reported}

${ }^{\mathrm{b}} \mathrm{F}$ female, $M$ male, $S$ spayed, $C$ castrated, $I$ intact

autologous cancer vaccine and 3 dogs treated with surgery alone).

The median survival time for dogs treated with surgery alone was 41 days (range, 2 to 145 days). The median survival time for dogs treated with MTD chemotherapy was 142 days (range, 26 to 241 days). The overall median survival time for dogs treated with the autologous cancer vaccine was 142 days (range, 61 to 373 days). Dogs treated with the autologous cancer vaccine or MTD chemotherapy had significantly $(P<0.001)$ longer survival than dogs treated with surgery alone. There was no significant difference in survival between dogs treated with the autologous cancer vaccine and those treated with MTD chemotherapy (Fig. 3). The 1-year survival rate was $12.5 \%$ for dogs treated with the autologous cancer vaccine, and $0 \%$ for dogs treated with surgery alone or MTD chemotherapy. Summary data for the three patient groups are presented in Table 3.

\section{Discussion}

Cancer is the leading cause of death in dogs [31]. Every year approximately 4 million dogs will be diagnosed with some form of cancer, and $50 \%$ of all dogs over the age of

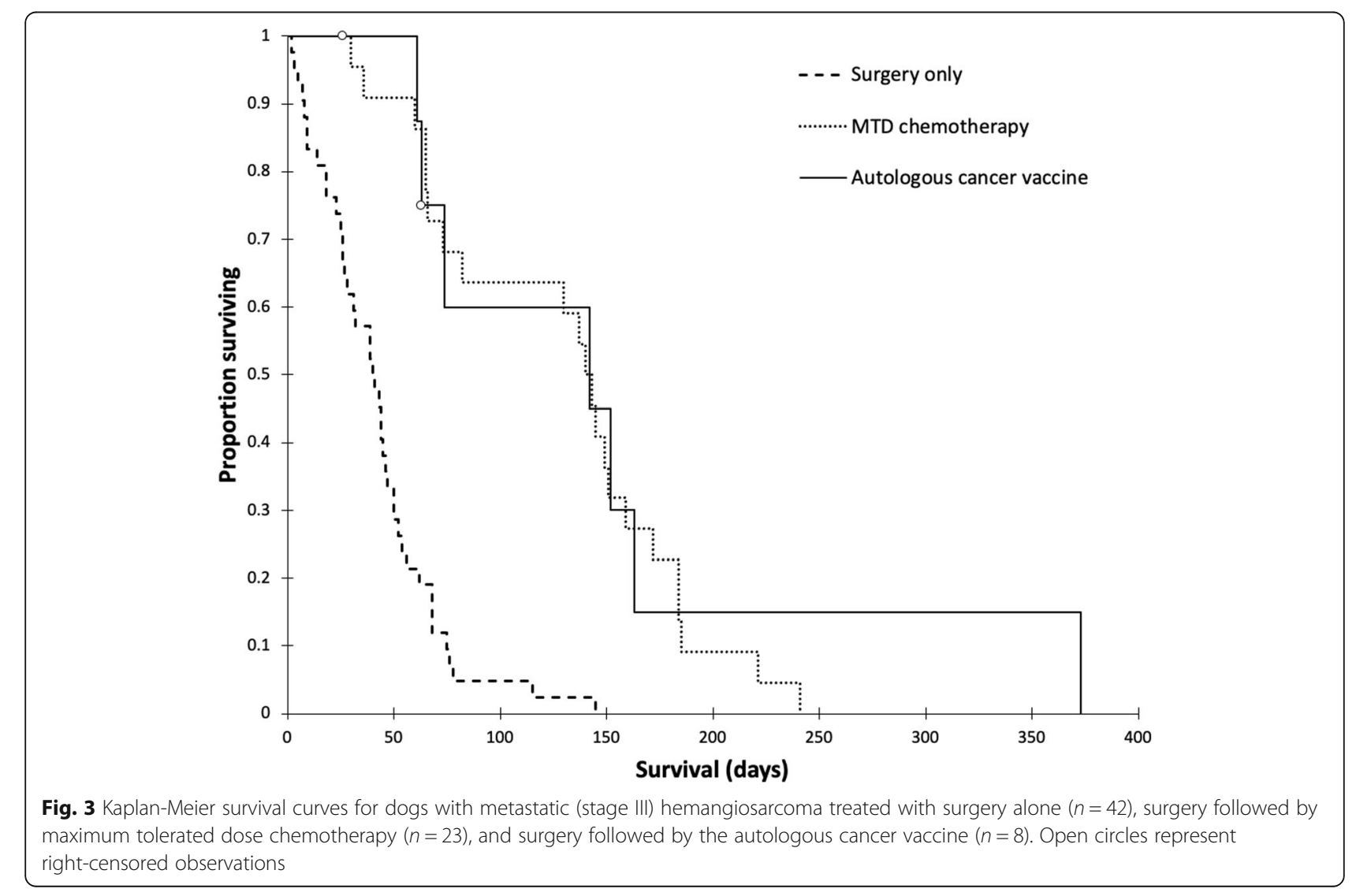


Table 3 Summary data from 73 dogs with metastatic hemangiosarcoma

\begin{tabular}{llll}
\hline & $\begin{array}{l}\text { Surgery alone } \\
(\boldsymbol{n}=\mathbf{4 2})\end{array}$ & $\begin{array}{l}\text { Surgery plus chemotherapy } \\
(\boldsymbol{n}=\mathbf{2 3})\end{array}$ & $\begin{array}{l}\text { Surgery plus autologous cancer vaccine } \\
(\boldsymbol{n}=\mathbf{8})\end{array}$ \\
\hline Age, years (mean \pm SD) & $10.3 \pm 2.00$ & $10.0 \pm 2.21$ & $7.6 \pm 1.71$ \\
Weight, kg (mean \pm SD) & $30.2 \pm 5.96$ & $31.6 \pm 9.84$ & $39.5 \pm 11.83$ \\
Adverse events (\%) & 0 & 43 & 0 \\
Hopitalizations (\%) & 0 & 17 & 0 \\
Median survival time, days & 41 & 142 & 142 \\
Survival range, days & 2 to 145 & 26 to 241 & 61 to 373 \\
Alive at $\mathbf{1}$ year (\%) & 0 & 0 & 12.5 \\
\hline
\end{tabular}

10 will die as a result of developing the disease [31, 32]. A major driving force behind these statistics is that, unfortunately, the therapeutic approaches used for treating dogs with cancer has lagged behind that of humans, resulting in sub-optimal clinical outcomes [33]. Immunotherapy offers a new approach to cancer treatment by re-educating the patient's immune system to combat the disease [34, 35]. This re-education process is accomplished by providing back stimulatory factors and tumor-associated antigens that allow for the host immune system to recognize the tumor as foreign. One such immunotherapeutic modality that is capable of performing such function is the autologous whole tissue cancer vaccine being developed by Torigen Pharmaceuticals [24].

Utilizing an in vitro assay of antigen presentation and DH82 canine monocyte-like cells, it was possible to highlight the mechanism of action of autologous cancer vaccines combined with MIM-SIS adjuvant. Major histocompatibility complex II (MHC-II) are molecules found on professional antigen-presenting cells (amongst others) that serve to present epitopes to $\mathrm{T}$ lymphocytes. Specifically, MHC-II molecules present longer peptidebased epitopes utilized for priming of $\mathrm{CD} 4+\mathrm{T}$ helper cells. Notably, MHC-I molecules facilitate priming of CD8 + cytotoxic T-cells that would be more directly relevant in the context of cancer immunotherapy, but no commercially available or literature published canine specific antibody is available at present for diagnostics. Beyond MHC, CD80 (or CD86) is a co- stimulatory molecule that increases in expression in response to antigen and facilitates $\mathrm{T}$-cell priming by co-ligation with CD28 T-cells. Together, MHC and CD80 represent two of the three required signals for $\mathrm{T}$ lymphocyte activation and differentiation; the third being a local cytokine environment. Accordingly, it is reasonable to rationalize that the ability to upregulate the expression of these surface molecules on canine monocytes could be indicative of greater potential $\mathrm{T}$ lymphocyte response in vivo. As such, this technique has been applied in numerous studies evaluating new vaccine technologies including recombinant antigens, novel adjuvants and variable formulation schemes
[36-42]. Specifically, the extent of major histocompatibility complex II (MHC-II) and CD80 co-stimulatory molecules were up-regulated in response to incubation with vaccine or relevant controls. These signals are traditional markers of antigen-presentation and are correlated to the ability to stimulate T-cell activation in vivo [43-45]. Notably, the MHC-II signal is indicative of helper T-cell activation, not cytotoxic $\mathrm{T}$-cell activation [46]; at this time, no validated canine-specific antibody is commercially available for MHC-I quantification, a marker of cytotoxic Tcell activation, via flow cytometry.

The results of the antigen presentation assay suggest that there is an immunostimulatory synergy between autologous cancer cells and MIM-SIS adjuvant. Specifically, while autologous cancer cells alone (GFT cells) are capable of stimulating a robust extent of antigen-presentation, they fail to provide the costimulatory signal that is absolutely required for $\mathrm{T}$ cell activation. Moreover, MIM-SIS alone promotes only weak co-stimulatory responses via CD80 surface expression. It is only when autologous cancer cells and MIM-SIS adjuvant are combined that there is a $53.7 \%$ increase in dual signaling of MHC-II and CD80 on canine cells, and thus a more robust potential for immune activation. The results of this assay indicate that there is no clear correlation between antigenpresentation/co-stimulation and tumor stage evaluated in an in vitro setting. In vivo, there could absolutely be a difference based upon the immunological status of that individual patient, which is highly dependent on manner factors even beyond the tumor type and grade. The most dominant discrepancy between in vitro and in vivo evaluations of the immune response would be the immunosuppressive tumor environment (negative impact), as well as tumor mutational burden (positive impact). Ultimately, the ability to upregulate CD80 and MHC-II would be derived from a balance of these two factors. Accordingly, this evidence, combined with our previous preclinical evaluations [26-29], provides justification for further research and warrants initial clinical validation in canine models. 
The population of dogs described herein was similar in age, weight, and male predominance described to previous reports of HSA [5, 11, 12, 14, 47]. The preponderance of German shepherd dogs observed herein has also been previously described [4, 11, 47, 48]. The dogs treated with immunotherapy in this study all tolerated the autologous cancer vaccine well, with no reported adverse events described. This group of dogs had an even lower proportion of adverse event rate than the $12 \%$ reported in a population of 93 dogs with various cancers treated with the autologous cancer vaccine immunotherapy after surgery [24]. This is in stark comparison to the observed proportion of adverse events (43\%) and hospitalizations (17\%) within the MTD chemotherapy group.

Although all of the deaths during the follow-up period were due to progressive HSA, the observed median survival time of 142 days for dogs with metastatic HSA represented a more than 3 -fold increase over the 41 day median survival time in the historical control group treated with surgery alone, and is more than 2.5-fold longer than the recently reported 54 day median survival time following surgery alone [9]. The majority of dogs treated with the adjuvanted autologous cancer vaccine had hemoperitoneum at presentation. Although there were no available comparison data from the historical control group, recent findings that hemoperitoneum does not affect survival time of dogs with HSA [49], suggests hemoperitoneum would be unlikely to influence outcome in the dogs described herein.

There were several limitations of this study. First, due to lack of available specimens, the in vitro work was conducted with surrogate HSA tumor vaccines created from patients not included in the clinical case evaluations and utilized a canine monocyte-like cell line rather than monocytes isolated from each specific dog. Although the upregulation of MCH-II and CD80 was demonstrated in the canine model, the findings were not specific to the dogs studied for survival outcome. However, the advantage of using the DH82 cell line is standardization and replication to facilitate vaccine-to-vaccine comparisons. If patient-specific monocytes were used, there would be two variables within the assay.

Another limitation was the retrospective nature of case evaluations. Because tumor specimens for the autologous cancer vaccine creation were submitted from a variety of clinicians (oncologists, surgeons, and general practitioners), pre-operative cancer staging, and posttreatment follow-up varied between patients. This limited the evaluation of vaccine efficacy in this population of dogs to simple survival analysis. Evaluating time to progression is an objective measurement of clinical efficacy that is free from bias introduced by dog owners' decisions on euthanasia. However, given the aggressive nature of HSA in dogs, the lengths of progression-free interval and overall survival are typically similar among different study populations $[10,15,50,51]$.

The small number of available dogs with stage III HSA treated with only surgery and the autologous cancer vaccine, and heterogeny among the cases, represent other limitations of the current study. Regardless, these preliminary findings are encouraging; the median survival time of vaccinated dogs was significantly longer than dogs treated with surgery alone. Results from a larger, prospective study will be needed to confirm these preliminary findings. In addition to treating dogs with metastatic HSA, studies of dogs with stage I and stage II are also warranted, as the adjuvanted autologous cancer vaccine may be more effective in dogs with a lower cancer burden, and vaccine effects on preventing metastatic disease could be demonstrated.

Compared with other techniques for creating autologous tumor vaccines, the method used herein to create the adjuvanted autologous cancer vaccine does not require culturing tumor cells, which allows for rapid manufacturing of the patient-specific vaccine. Culturing tumor cells increases the chances for microbial contamination of the vaccine product. Using mechanical dissociation of tumor tissue also preserves TAA which may induce a more robust immunologic response.

The autologous cancer vaccine protocol used here, administering 3 weekly subcutaneous autologous cancer vaccine doses, allows a patient with stage III HSA to complete the course of therapy quickly, compared to dogs undergoing a standard anthracycline (doxorubicin or epirubicin) chemotherapy protocol receiving an intravenous injection every 3 weeks for 5 to 6 doses [11]. The autologous cancer vaccine also provides a significant survival advantage over surgery alone for dogs with stage III HSA, with minimal risk for adverse events. Many dog owners are concerned about adverse events associated with chemotherapy [20], and the anthracycline drugs have been associated with acute allergic reactions, GI upset, neutropenia, thrombocytopenia, and rarely cardiotoxicity $[10,12,19,52-60]$. In the present study, adverse events were common in the historical control group treated with standard anthracycline chemotherapy. Additionally, for many dog owners, the time and financial commitments associated with chemotherapy for stage III HSA are not feasible, and the outcome expectations also factor into the decision-making process [61]. Treatment with the autologous cancer vaccine as reported here, and previously described, has a low risk of adverse events [24], and may be more affordable than chemotherapy.

This method of generating an adjuvanted autologous cancer vaccine represents an individualized form of immunotherapy, presenting a range of tumor-specific and host-specific antigens to the patient's immune system, that may be appropriate for any solid tumor where 
sufficient cells can be collected for vaccine preparation. This is in contrast to other immunotherapy options, such as the canine melanoma vaccine and canine osteosarcoma vaccine, which present a single antigen to the patient's immune system (human tyrosinase and HER2/ neu, respectively) [62, 63].

\section{Conclusions}

The data presented herein demonstrate that immunotherapy with the adjuvanted autologous cancer vaccine is capable of up-regulating MHC-II and CD80 in cultured canine monocyte-derived cells, which are important stimulatory molecules in generating an immune response, and the vaccine improves survival time in dogs with metastatic (stage III) HSA when compared to surgical treatment alone. The autologous cancer vaccine-treated dogs had survival similar to those dogs treated with maximum tolerated dose chemotherapy without any observed adverse events. This autologous cancer vaccine represents an effective form of individualized immunotherapy that is an appealing option for dog owners not wanting to pursue adjuvant chemotherapy for HSA.

\section{Methods}

\section{Materials}

All reagents were used as obtained from commercial sources without further purification. DH82 canine malignant histiocytoma cells (macrophage-like, CRL-10, 389) were purchased from ATCC (Manassas, VA, USA). Anti-CD80 (Brilliant Violet 421, clone 16-10A1) was obtained from BioLegend (San Diego, CA, USA). AntiMHC-II (APC, YKIX334.2) and Live/Dead Fixable Blue Stain Kit (L34962) were obtained from Thermo Fisher Scientific (Waltham, MA, USA).

\section{DH82 antigen presentation assay}

The ability of autologous cancer vaccines to facilitate antigen presentation (MHC-II) and co-stimulation (CD80) was evaluated in-vitro using DH82 canine macrophages and flow cytometry. DH82 cells were maintained at $37{ }^{\circ} \mathrm{C}$, $5 \% \mathrm{CO}_{2} / 95 \%$ air atmosphere and approximately $85 \%$ relative humidity. DH82 cell culture media consisted of Dulbecco's Modified Eagles Media, 15\% heat-inactivated fetal bovine serum (VWR, Radnor, PA, USA), 1\% SG-200 (GE Healthcare, Chicago, IL, USA), 1\% sodium pyruvate (GE Healthcare), 1\% antibiotic-antimycotic (Thermo Fisher Scientific). Prior to performing the assay, DH82 cells were seeded overnight at $2.5 \mathrm{e} 5$ cells/well in 24-well non-treated cell culture dishes. The antigen presentation assay was performed by incubating autologous cancer vaccine preparations $(0.25 \mathrm{e} 6$ cells $/$ well, $0.5 \mathrm{mg} / \mathrm{mL}$ MIM-SIS) or relevant controls with cells for 48 hours (performed in triplicate). Autologous cancer vaccines were prepared for thirteen unique HSA samples (Table 1) as previously described [24], from submitted patient samples with a sufficient amount of tissue available after creation of their vaccine for clinical use. After 48 hours, cells are harvested and prepared for analysis by flow cytometry using the following stains: Live/Dead Fixable, anti-CD80 Brilliant Violet 421 and anti-MHC-II APC. Cells were analyzed using a Becton-Dickinson LSR II flow cytometer (Franklin Lakes, NJ, USA) at the University of Connecticut Health Center Flow Cytometry Core (Farmington, CT, USA) with the FCS Express 7 software package (DeNovo Software, Pasadena, CA, USA). Fluorescence minus one (FMO) controls were utilized to established gating scheme.

\section{Case selection}

The case accession database at Torigen Pharmaceuticals, Inc. was queried to identify dogs diagnosed with stage III HSA between January 2015 and January 2020 that were treated with surgery followed by the adjuvanted autologous cancer vaccine only.

Dogs were eligible for inclusion in this study if they had a histopathological diagnosis of non-cutaneous HSA and evidence of distant metastasis (i.e., stage III disease) identified via imaging, cytopathology or histopathology, and were treated by surgery and the adjuvanted autologous cancer vaccine only. Dogs were excluded from study if they were diagnosed with cutaneous HSA, had visceral, subcutaneous or intramuscular HSA with no evidence of metastasis (i.e., stage I or II), did not receive all three doses of the autologous cancer vaccine, received adjuvant chemotherapy, or had incomplete outcome information available. Histopathologic diagnosis was reported by board-certified veterinary pathologists via commercial laboratory services. Patient data collected included signalment, body weight, histology results, primary tumor location, adverse events reported after autologous tumor vaccine administration, and survival from the time of tumor removal. Follow up information on each dog was obtained through direct communication with the submitting veterinarian. Adverse events were classified based on the Veterinary Cooperative Oncology Group common terminology criteria for adverse events (VCOGCTCAE) [64].

\section{Historical controls}

The historical controls cases were dogs identified between 2011 and 2018 with stage III HSA that were either treated with surgery alone, or surgery followed with standard maximum tolerated dose (MTD) anthracyclinebased chemotherapy. The outcomes of these dogs have been previously published [10], and the authors provided a raw data set which included signalment, adverse events and hospitalization reported after chemotherapy administration, and survival from the time of tumor removal. Adverse events were classified based on the VCOGCTCAE [64]. 


\section{Vaccine protocol}

Preparation of the adjuvanted autologous cancer vaccine has been described elsewhere [24]. Briefly, unfixed tumor tissue was mechanically dissociated, fixed with glutaraldehyde, and following multiple washing steps, the fixed cells were combined with MIM-SIS to create the final vaccine product. Veterinarians were instructed to give the vaccine as a subcutaneous injection, as three $1 \mathrm{~mL}$ doses, at weekly intervals. The attending veterinarian was advised to monitor the dog for acute $\mathrm{AE}$ for 30 minutes after each of the three injections. At hospital discharge, dog owners were informed of possible vaccine reactions, and instructed to report any observed abnormalities immediately upon their occurrence. Written owner informed consent was obtained before the vaccine was administered.

\section{Statistical analysis}

In-vitro data are expressed as mean \pm standard deviation (SD). Means of multiple groups were compared with the one-way analysis of variance (ANOVA), followed by post hoc Tukey's pairwise comparisons. All probability values are two-sided, and values of $p<0.05$ were considered statistically significant. Statistical analyses were carried out using the GraphPad Prism 7 software package.

Among treatment groups, the variance of continuous variables was compared using Levene's test, and proportions were compared using the Marascuilo procedure. Dogs were right-censored from survival analysis if they were lost to follow-up, died from an unrelated cause, or were still alive at the time of data analysis. Progressionfree survival was not calculated due to insufficient information in the database or attending veterinarian medical records. Survival estimates were generated using the Kaplan-Meier method, and survival curves were compared using the Log-Rank test. Statistical testing was done using XLSTAT Life Science (Addinsoft, 2020, New York, USA). $P$ values $<0.05$ were used to indicate statistical significance. Results are reported as mean \pm standard deviation unless otherwise noted.

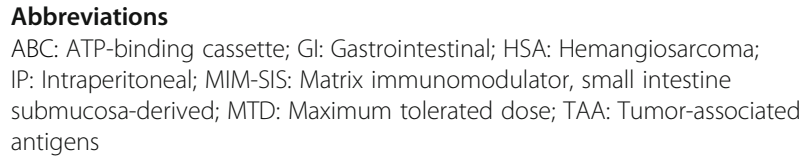

\section{Acknowledgements}

Special thanks to Laura Marconato, DVM, Dipl. ECVIM-CA (oncology), Professore Associato, Dipartimento di Scienze Mediche Veterinarie, Università di Bologna for providing the historical data set.

\section{Authors' contributions}

$\mathrm{RC}$ and FE performed the in vitro assays and analyzed and interpreted the flow cytometry data. ML analyzed and interpreted the patient outcome data. MS and AK were instrumental in the conception of and subsequent revisions of this work. All authors read and approved the final manuscript.

\section{Funding}

There was no external funding for this study.

\section{Availability of data and materials}

The datasets generated and/or analyzed during the current study are available from the corresponding author on reasonable request.

\section{Ethics approval and consent to participate}

The retrospective study described here involved review of medical records from privately-owned dogs, all receiving care as prescribed by licensed veterinarians. Under such circumstances, U. S. Federal regulatory agencies do not require formal review by an Institutional Animal Care and Use Committee (IACUC) [53]. Ethical assurance regarding the clinical use of the investigational, commercially available, autologous cancer vaccine was provided through a mechanism of written informed consent from dog owners, as required by the USDA for unlicensed veterinary biologics.

\section{Consent for publication}

Not applicable.

\section{Competing interests}

All authors are affiliated with Torigen Pharmaceuticals, Inc.

\section{Author details}

${ }^{1}$ Torigen Pharmaceuticals, Inc, 400 Farmington Avenue R1855 CB129, 06032 Farmington, CT, USA. ${ }^{2}$ Office of the Vice President for Research, University of Kentucky, 445 Bowman Hall, KY 40506-0032 Lexington, USA.

Received: 29 April 2020 Accepted: 9 November 2020

Published online: 18 November 2020

\section{References}

1. Lamerato-Kozicki AR, Helm KM, Jubala CM, Cutter GC, Modiano JF. Canine hemangiosarcoma originates from hematopoietic precursors with potential for endothelial differentiation. Exp Hematol. 2006;34(7):870-8.

2. Tamburini BA, Phang TL, Fosmire SP, Scott MC, Trapp SC, Duckett MM, Robinson SR, Slansky JE, Sharkey LC, Cutter GR, et al. Gene expression profiling identifies inflammation and angiogenesis as distinguishing features of canine hemangiosarcoma. BMC Cancer. 2010;10:619.

3. Kim JH, Graef AJ, Dickerson EB, Modiano JF. Pathobiology of Hemangiosarcoma in Dogs: Research Advances and Future Perspectives. Vet Sci. 2015;2(4):388-405.

4. Brown NO, Patnaik AK, MacEwen EG. Canine hemangiosarcoma: retrospective analysis of 104 cases. J Am Vet Med Assoc. 1985;186(1):56-8.

5. Batschinski K, Nobre A, Vargas-Mendez E, Tedardi MV, Cirillo J, Cestari G, Ubukata R, Dagli MLZ. Canine visceral hemangiosarcoma treated with surgery alone or surgery and doxorubicin: 37 cases (2005-2014). Can Vet J. 2018;59(9):967-72.

6. Wood CA, Moore AS, Gliatto JM, Ablin LA, Berg RJ, Rand WM. Prognosis for dogs with stage I or II splenic hemangiosarcoma treated by splenectomy alone: 32 cases (1991-1993). J Am Anim Hosp Assoc. 1998;34(5):417-21.

7. Prymak C, McKee LJ, Goldschmidt MH, Glickman LT. Epidemiologic, clinical, pathologic, and prognostic characteristics of splenic hemangiosarcoma and splenic hematoma in dogs: 217 cases (1985). J Am Vet Med Assoc. 1988; 193(6):706-12.

8. Cleveland MJ, Casale S. Incidence of malignancy and outcomes for dogs undergoing splenectomy for incidentally detected nonruptured splenic nodules or masses: 105 cases (2009-2013). J Am Vet Med Assoc. 2016; 248(11):1267-73.

9. Wendelburg KM, Price LL, Burgess KE, Lyons JA, Lew FH, Berg J. Survival time of dogs with splenic hemangiosarcoma treated by splenectomy with or without adjuvant chemotherapy: 208 cases (2001-2012). J Am Vet Med Assoc. 2015;247(4):393-403.

10. Marconato L, Chalfon C, Finotello R, Polton G, Vasconi ME, Annoni M, Stefanello D, Mesto P, Capitani O, Agnoli C, et al. Adjuvant anthracyclinebased vs metronomic chemotherapy vs no medical treatment for dogs with metastatic splenic hemangiosarcoma: A multi-institutional retrospective study of the Italian Society of Veterinary Oncology. Veterinary Comparative Oncology. 2019;17(4):537-44.

11. Clifford CA, Mackin AJ, Henry CJ. Treatment of canine hemangiosarcoma: 2000 and beyond. J Vet Intern Med. 2000;14(5):479-85.

12. Kim SE, Liptak JM, Gall TT, Monteith GJ, Woods JP. Epirubicin in the adjuvant treatment of splenic hemangiosarcoma in dogs: 59 cases (1997-2004). J Am Vet Med Assoc. 2007;231(10):1550-7. 
13. Gardner $\mathrm{HL}$, London CA, Portela RA, Nguyen S, Rosenberg MP, Klein MK, Clifford C, Thamm DH, Vail DM, Bergman P, et al. Maintenance therapy with toceranib following doxorubicin-based chemotherapy for canine splenic hemangiosarcoma. BMC Vet Res. 2015;11:131.

14. Hammer AS, Couto CG, Filppi J, Getzy D, Shank K. Efficacy and toxicity of VAC chemotherapy (vincristine, doxorubicin, and cyclophosphamide) in dogs with hemangiosarcoma. J Vet Intern Med. 1991;5(3):160-6.

15. Alexander CK, Cronin KL, Silver M, Gardner HL, London C. The addition of metronomic chemotherapy does not improve outcome for canine splenic haemangiosarcoma. J Small Anim Pract. 2019;60(1):32-7.

16. Finotello R, Stefanello D, Zini E, Marconato L. Comparison of doxorubicincyclophosphamide with doxorubicin-dacarbazine for the adjuvant treatment of canine hemangiosarcoma. Vet Comp Oncol. 2017;15(1):25-35.

17. Sorenmo KU, Baez JL, Clifford CA, Mauldin E, Overley B, Skorupski K, Bachman R, Samluk M, Shofer F. Efficacy and toxicity of a dose-intensified doxorubicin protocol in canine hemangiosarcoma. J Vet Intern Med. 2004; 18(2):209-13.

18. Khammanivong A, Gorden BH, Frantz AM, Graef AJ, Dickerson EB. Identification of drug-resistant subpopulations in canine hemangiosarcoma. Vet Comp Oncol. 2016;14(3):e113-25.

19. Marrington AM, Killick DR, Grant IA, Blackwood L. Toxicity associated with epirubicin treatments in a large case series of dogs. Vet Comp Oncol. 2012; 10(2):113-23.

20. Williams J, Phillips C, Byrd HM. Factors Which Influence Owners When Deciding to Use Chemotherapy in Terminally III Pets. Animals (Basel).2017; 7(3):18. Published 2017 Mar 7. https://doi.org/10.3390/ani7030018.

21. U'Ren LW, Biller BJ, Elmslie RE, Thamm DH, Dow SW. Evaluation of a novel tumor vaccine in dogs with hemangiosarcoma. J Vet Intern Med. 2007;21(1):113-20.

22. Konduri V, Halpert MM, Baig YC, Coronado R, Rodgers JR, Levitt JM, Cerroni B, Piscoya S, Wilson N, DiBernardi L, et al. Dendritic cell vaccination plus low-dose doxorubicin for the treatment of spontaneous canine hemangiosarcoma. Cancer Gene Ther. 2019;26(9-10):282-91.

23. Yannelli JR, Wouda R, Masterson TJ, Avdiushko MG, Cohen DA. Development of an autologous canine cancer vaccine system for resectable malignant tumors in dogs. Vet Immunol Immunopathol. 2016;182:95-100.

24. Crossley RA, Matz A, Dew T, Kalinauskas A, Faucette N, Poff B, Silbart LK, Suckow MA. Safety Evaluation of Autologous Tissue Vaccine Cancer Immunotherapy in a Canine Model. Anticancer Res. 2019;39(4):1699-703.

25. Brown BN, Ratner BD, Goodman SB, Amar S, Badylak SF. Macrophage polarization: an opportunity for improved outcomes in biomaterials and regenerative medicine. Biomaterials. 2012;33(15):3792-802.

26. Suckow MA, Hall P, Wolter W, Sailes V, Hiles MC. Use of an extracellular matrix material as a vaccine carrier and adjuvant. Anticancer Res. 2008;28(5A):2529-34.

27. Suckow MA, Wolter WR, Sailes VT. Inhibition of prostate cancer metastasis by administration of a tissue vaccine. Clin Exp Metastasis. 2008;25(8):913-8.

28. Suckow MA, Wolter WR, Pollard M. Prevention of de novo prostate cancer by immunization with tumor-derived vaccines. Cancer Immunol Immunother. 2005;54(6):571-6.

29. Suckow MA, Heinrich J, Rosen ED. Tissue vaccines for cancer. Expert Rev Vaccines. 2007;6(6):925-37.

30. Disis ML. Mechanism of action of immunotherapy. Semin Oncol. 2014 41(Suppl 5):3-13.

31. Davis BW, Ostrander EA. Domestic dogs and cancer research: a breed-based genomics approach. ILAR J. 2014;55(1):59-68.

32. Schiffman JD, Breen M. Comparative oncology: what dogs and other species can teach us about humans with cancer. Philos Trans R Soc Lond B Biol Sci.2015;370(1673):20140231. https://doi.org/10.1098/rstb.2014.0231.

33. Addissie S, Klingemann H. Cellular Immunotherapy of Canine Cancer. Vet Sci. 2018:5(4):100. Published 2018 Dec 6. https://doi.org/10.3390/ vetsci5040100

34. Kaufman HL, Atkins MB, Subedi P, Wu J, Chambers J, Joseph Mattingly T 2nd, Campbell JD, Allen J, Ferris AE, Schilsky RL, et al. The promise of Immuno-oncology: implications for defining the value of cancer treatment. J Immunother Cancer. 2019:7(1):129.

35. Sambi M, Bagheri L, Szewczuk MR. Current Challenges in Cancer Immunotherapy: Multimodal Approaches to Improve Efficacy and Patient Response Rates. J Oncol. 2019;2019:4508794

36. Ilkovitch D, Ostrand-Rosenberg S. MHC class II and CD80 tumor cell-based vaccines are potent activators of type 1 CD4 + T lymphocytes provided they do not coexpress invariant chain. Cancer Immunol Immunother. 2004; 53(6):525-32.
37. Wu C, Liu Y, Zhao Q, Chen G, Chen J, Yan X, Zhou YH, Huang Z. Soluble CD40 ligand-activated human peripheral $B$ cells as surrogated antigen presenting cells: A preliminary approach for anti-HBV immunotherapy. Virol J. 2010;7:370.

38. Vono M, Lin A, Norrby-Teglund A, Koup RA, Liang F, Lore K. Neutrophils acquire the capacity for antigen presentation to memory CD4(+) T cells in vitro and ex vivo. Blood. 2017;129(14):1991-2001.

39. Lee OE, Ko YT, Kim EJ, Lee KH, Song YN, Kwon JM, Kim YM, Perez MC, Kang DR. SM: Roles of major histocompatibility complex class II in inducing protective immune responses to influenza vaccination. J Virol. 2014;88(14):7764-75.

40. Aguilera R, Saffie C, Tittarelli A, Gonzalez FE, Ramirez M, Reyes D, Pereda C, Hevia D, Garcia T, Salazar L, et al. Heat-shock induction of tumor-derived danger signals mediates rapid monocyte differentiation into clinically effective dendritic cells. Clin Cancer Res. 2011;17(8):2474-83.

41. Zhai J, Gao W, Zhao L, Gao Z, Jiang X, Lu C. Dendritic cell vaccine with Ag85A enhances anti-colorectal carcinoma immunity. Exp Ther Med. 2018;16(6):5123-9.

42. Zhang C, Wang GX, Zhu B. Application of antigen presenting cell-targeted nanovaccine delivery system in rhabdovirus disease prophylactics using fish as a model organism. J Nanobiotechnology. 2020;18(1):24.

43. Mendonca PHB, da Rocha R, Moraes JBB, LaRocque-de-Freitas IF, Logullo J, Morrot A, Nunes MP, Freire-de-Lima CG, Decote-Ricardo D. Canine Macrophage DH82 Cell Line As a Model to Study Susceptibility to Trypanosoma cruzi Infection. Front Immunol. 2017;8:604.

44. de Charette M, Marabelle A, Houot R. Turning tumour cells into antigen presenting cells: The next step to improve cancer immunotherapy? Eur J Cancer. 2016;68:134-47.

45. Bodewes R, Geelhoed-Mieras MM, Heldens JG, Glover J, Lambrecht BN, Fouchier RA, Osterhaus AD, Rimmelzwaan GF. The novel adjuvant CoVaccineHT increases the immunogenicity of cell-culture derived influenza $\mathrm{A} / \mathrm{H} 5 \mathrm{~N} 1$ vaccine and induces the maturation of murine and human dendritic cells in vitro. Vaccine. 2009;27(49):6833-9.

46. Zhu J, Paul WE. CD4 T cells: fates, functions, and faults. Blood. 2008;112(5):1557-69.

47. Moore AS, Rassnick KM, Frimberger AE. Evaluation of clinical and histologic factors associated with survival time in dogs with stage II splenic hemangiosarcoma treated by splenectomy and adjuvant chemotherapy: 30 cases (2011-2014). J Am Vet Med Assoc. 2017;251(5):559-65.

48. Ng CY, Mills JN. Clinical and haematological features of haemangiosarcoma in dogs. Aust Vet J. 1985:62(1):1-4.

49. Patten SG, Boston SE, Monteith GJ. Outcome and prognostic factors for dogs with a histological diagnosis of splenic hematoma following splenectomy: 35 cases (2001-2013). Can Vet J. 2016;57(8):842-6.

50. Kahn SA, Mullin CM, de Lorimier LP, Burgess KE, Risbon RE, Fred RM 3rd, Drobatz K, Clifford CA. Doxorubicin and deracoxib adjuvant therapy for canine splenic hemangiosarcoma: a pilot study. Can Vet J. 2013;54(3):237-42.

51. Vail DM, MacEwen EG, Kurzman ID, Dubielzig RR, Helfand SC, Kisseberth WC, London CA, Obradovich JE, Madewell BR, Rodriguez CO Jr, et al. Liposome-encapsulated muramyl tripeptide phosphatidylethanolamine adjuvant immunotherapy for splenic hemangiosarcoma in the dog: a randomized multi-institutional clinical trial. Clin Cancer Res. 1995;1(10): $1165-70$.

52. Phillips BS, Kraegel SA, Simonson E, Madewell BR. Acute reactions in dogs treated with doxorubicin: increased frequency with the use of a generic formulation. J Vet Intern Med. 1998;12(3):171-2.

53. Ogilvie GK, Reynolds HA, Richardson RC, Withrow SJ, Norris AM, Henderson RA, Klausner JS, Fowler JD, McCaw D. Phase II evaluation of doxorubicin for treatment of various canine neoplasms. J Am Vet Med Assoc. 1989;195(11):1580-3.

54. Sorenmo K, Duda L, Barber L, Cronin K, Sammarco C, Usborne A, Goldschmidt M, Shofer F. Canine hemangiosarcoma treated with standard chemotherapy and minocycline. J Vet Intern Med. 2000;14(4):395-8.

55. Ogilvie GK, Richardson RC, Curtis CR, Withrow SJ, Reynolds HA, Norris AM, Henderson RA, Klausner JS, Fowler JD, MCCaw D. Acute and short-term toxicoses associated with the administration of doxorubicin to dogs with malignant tumors. J Am Vet Med Assoc. 1989;195(11):1584-7.

56. Banco B, Grieco V, Servida F, Giudice C. Sudden death in a dog after doxorubicin chemotherapy. Vet Pathol. 2011;48(5):1035-7.

57. Gallay-Lepoutre J, Belanger MC, Nadeau ME. Prospective evaluation of Doppler echocardiography, tissue Doppler imaging and biomarkers measurement for the detection of doxorubicin-induced cardiotoxicity in dogs: A pilot study. Res Vet Sci. 2016;105:153-9.

58. Loar AS, Susaneck SJ. Doxorubicin-induced cardiotoxicity in five dogs. Semin Vet Med Surg (Small Anim). 1986;1(1):68-71. 
59. Surachetpong SD, Teewasutrakul P, Rungsipipat A. Serial measurements of cardiac troponin I (cTnl) in dogs treated with doxorubicin. Jpn J Vet Res. 2016;64(4):221-33.

60. Tomlinson CW, Godin DV, Rabkin SW. Adriamycin cardiomyopathy: implications of cellular changes in a canine model with mild impairment of left ventricular function. Biochem Pharmacol. 1985;34(22):4033-41.

61. Brockman BK, Taylor VA, Brockman CM. The price of unconditional love: Consumer decision making for high-dollar veterinary care. J Business Res. 2008;61:397-405.

62. Grosenbaugh DA, Leard AT, Bergman PJ, Klein MK, Meleo K, Susaneck S, Hess PR, Jankowski MK, Jones PD, Leibman NF, et al. Safety and efficacy of a xenogeneic DNA vaccine encoding for human tyrosinase as adjunctive treatment for oral malignant melanoma in dogs following surgical excision of the primary tumor. Am J Vet Res. 2011;72(12):1631-8.

63. Mason NJ, Gnanandarajah JS, Engiles JB, Gray F, Laughlin D, GaurnierHausser A, Wallecha A, Huebner M, Paterson Y. Immunotherapy with a HER2-Targeting Listeria Induces HER2-Specific Immunity and Demonstrates Potential Therapeutic Effects in a Phase I Trial in Canine Osteosarcoma. Clin Cancer Res. 2016;22(17):4380-90.

64. Caballero-Banos M, Benitez-Ribas D, Tabera J, Varea S, Vilana R, Bianchi L, Ayuso JR, Pages M, Carrera G, Cuatrecasas M, et al. Phase II randomised trial of autologous tumour lysate dendritic cell plus best supportive care compared with best supportive care in pre-treated advanced colorectal cancer patients. Eur J Cancer. 2016;64:167-74.

\section{Publisher's Note}

Springer Nature remains neutral with regard to jurisdictional claims in published maps and institutional affiliations.

Ready to submit your research? Choose BMC and benefit from:

- fast, convenient online submission

- thorough peer review by experienced researchers in your field

- rapid publication on acceptance

- support for research data, including large and complex data types

- gold Open Access which fosters wider collaboration and increased citations

- maximum visibility for your research: over $100 \mathrm{M}$ website views per year

At BMC, research is always in progress.

Learn more biomedcentral.com/submissions 